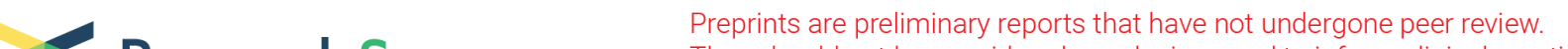 $\begin{array}{ll}\text { Research Square } & \begin{array}{l}\text { They should not be considered conclusive, used to inform clinical practice, } \\ \text { or referenced by the media as validated information. }\end{array}\end{array}$
}

\section{Family Relationships, Personality Disorder Functioning Styles and Emotional States in Generalized Anxiety and Major Depressive Disorders}

\section{Zhenghe YU ( $\nabla$ yuzhcoo@sina.com )}

Zhejiang University School of Medicine

\section{You Xu}

Zhejiang University School of Medicine

\section{Qisha ZHU}

Zhejiang University School of Medicine

Hongjing MAO

Zhejiang University School of Medicine

\section{Bingren ZHANG}

Hangzhou Normal University College of Medicine

\section{Xu SHAO}

Zhejiang University College of Medicine

\section{Wei WANG}

Norwegian University of Science and Technology

\section{Research Article}

Keywords: Family relationship, Generalized anxiety disorder, Major depressive disorder, Parenting style

Posted Date: May 13th, 2021

DOI: https://doi.org/10.21203/rs.3.rs-493588/v1

License: (9) (i) This work is licensed under a Creative Commons Attribution 4.0 International License. Read Full License 


\section{Abstract}

Objective: Family relationship affects personality development and emotional regulation, which might be more pronounced in generalized anxiety (GAD) and major depressive (MD) disorders.

Method: Thirty patients with GAD, $31 \mathrm{MD}$, and 32 healthy volunteers answered the Family Relationship Questionnaire (FRQ), the Parker Personality Measure (PERM), and the Hamilton Anxiety and Depression Rating Scales.

Results: Compared to healthy controls, both patient groups scored higher on FRQ Paternal Abuse and Paternal Dominance, and lower on Maternal Freedom Release; GAD in addition scored lower on Maternal Abuse and Maternal Dominance. All PERM scale scores except Narcissistic were higher in MD than those in GAD, and all scale scores except Schizotypal and Narcissistic were higher in MD than in controls. Maternal Encouragement was associated with the Paranoid and Schizotypal styles, and Maternal Freedom Release the Avoidant and Borderline in GAD; and Maternal Encouragement the Paranoid, Paternal Dominance the Avoidant, Paternal Freedom Release (-) and Maternal Freedom Release the anxiety, and the Dependent the depression in MD.

Conclusions: Our study demonstrates different associations between family relationships and personality traits/ emotional states in MD and GAD, suggesting different forms of family therapy for the two disorders.

\section{Introduction}

Parental bonding style is the perceivable attitudes of parents towards child, it creates an emotional climate where parents' behaviors are expressed [1], and it plays an important role in the adulthood psychological functioning (such as emotional and personality aspects) of that child [2-3]. Many studies have shown that decreased maternal care, and increased paternal overprotection, rejection or control are related to the childhood or later adulthood behavioral and emotional problems, such as anxiety and depression $[4,5,6]$. Others also have demonstrated that the perceived parental pressure is correlated with trait anxiety and depersonalization in high school students [7], and adolescents with perceived parental warm are more likely to be free from depression after stressful life events [8]. Parental rejection and overprotection were found in anxiety disorders, such as generalized anxiety (GAD) and separation anxiety disorders $[9,10,11]$. Neglecting, rejecting, over-criticizing or disapproving from parents most likely contributed to the development of depression $[12,13]$.

Regarding personality aspect, high paternal overprotection or low care was associated with the obsessive-compulsive personality disorder [14], maternal overprotection and authoritarianism were associated with an increased risk of the antisocial personality disorder [3]. The childhood abuse and neglect in general were associated with the substance misuse in adolescents, and violence and psychopathy in adults $[15,16]$. Compared to healthy adolescents, personality disorder patients perceived 
less parental care, more freedom control and more autonomy denial, and reported higher levels of disordered personality traits or personality disorder functioning styles $[17,18]$.

The affective disorders were usually interrelated with abnormal personality traits such as high neuroticism and low extraversion $[19,20]$, especially in their extremes, for instance, GAD $[21,22]$ and the major depressive disorder (MD) $[23,24]$. Moreover, there was an approximately $50 \%$ overlap between anxiety and depression [25] which might be due to their common personality traits, such as the high harm avoidance and self-directedness [26, 27], and low conscientiousness and sociability [28, 29]. However, depression and anxiety might have their different personality traits, for example, depression had a large association with the lack of positive affectivity, while social anxiety had moderately strong associations with both low sociability and lack of positive affectivity [30]. The depressive disorder had consistent abnormalities of neuroticism, extraversion and conscientiousness, while the anxiety disorder mainly of neuroticism [31]. Moreover, compared to GAD, the treatment-resistant depression displayed higher neuroticism-anxiety [28].

Up to date, there has been no clear picture regarding the family relationship contributions to personality traits or emotional states in MD and GAD. In the current study, we would like to hypothesize that: (1) GAD and MD have different negative family relationships that MD has less encouragement while GAD with more dominance from parents; (2) MD has broader and severer personality abnormalities than GAD does; (3) the associations between family relationships, personality disorder functioning styles, and emotional states are different in GAD and MD. Therefore, we invited patients with MD and GAD, as well as healthy volunteers to undergo tests of the Family Relationship Questionnaire (FRQ) [32] to evaluate the core features of the experienced family relationships up to 16 years old, the Parker Personality Measure (PERM) [33] to measure the personality disorder functioning styles, and the Hamilton Anxiety Rating Scale [34] and the Hamilton Depression Rating Scale [35] to assess the concurrent emotional states.

\section{Method}

\subsection{Participants}

Besides 32 healthy volunteers, we enrolled $30 \mathrm{GAD}$ and $31 \mathrm{MD}$ patients in the current study, and their detailed demographic and clinical characteristics are shown in Table 1. There was no significant age ( $F$ $[2,84]=2.29$, mean squared error $(\mathrm{MSE})=188.92, \mathrm{p}=.11)$ or gender $\left(\chi^{2}=.18, d f=2, p=.92\right)$ difference among three groups of participant. A semi-structured interview was implemented on each healthy volunteer to make sure that they were not suffering from any psychiatric or neurological problems. Diagnoses were obtained by two experienced psychiatrists (ZY and WW) according to DSM- 5 criteria for GAD and MD [36]. Patients with organic brain lesions, drug/ alcohol abuse or other types of psychiatric disorders were excluded from the study. The study was approved by a local ethics committee, and all participants gave their written informed consent to participate in this study. 
Table 1

Demographic/ clinical features in healthy volunteers (controls, $n=32$ ), and patients with Generalized Anxiety Disorder $(G A D, n=30)$ and Major Depressive Disorder $(M D, n=31)$.

\begin{tabular}{|llll|}
\hline & Controls & GAD & MD \\
\hline Age (in years; mean \pm S.D, range) & $36.23 \pm$ & $40.96 \pm$ & $36.89 \pm$ \\
& $6.97,23 \sim$ & $9.38,25 \sim$ & $10.83,18$ \\
Gender (male: female) & 50 & 54 & $\sim 56$ \\
\hline Educational level (in years, mean \pm S.D.) & $14: 18$ & $12: 18$ & $14: 17$ \\
Benzodiazepine (patient number) & $13.48 \pm$ & $11.23 \pm$ & $12.35 \pm$ \\
Selective serotonin reuptake inhibitor or serotonin and & - & 2.36 & 2.58 \\
norepinephrine reuptake inhibitor (patient number) & & 30 & 27 \\
\hline
\end{tabular}

\subsection{Measures}

Participants were asked to complete the following four questionnaires in Chinese in a quiet room.

\section{A. The Family Relationship Questionnaire (FRQ)}

This inventory is a self-report measure of 43 items, with five factors (scales) namely, Paternal/ Maternal Encouragement (5 items each), Paternal/ Maternal Abuse (5 items each), Paternal/ Maternal Freedom Release (5 items each), General Attachment (5 items), and Paternal/ Maternal Dominance (4 items each). Each FRQ item is marked by a 5-point Likert scale (1 - very unlike me, 2 - moderately unlike me, 3 somewhat unlike and like me, 4 - moderately like me and 5 - very like me). The Cronbach internal reliabilities (internal alphas) of the scales ranged from .64 to .83 in a Chinese study [32].

\section{B. The Parker Personality Measure (PERM)}

This instrument measures 11 functioning styles of paranoid, schizoid, schizotypal, antisocial, borderline, histrionic, narcissistic, avoidant, dependent, obsessive-compulsive, and passive-aggressive personality disorders [33]. Each PERM item is marked by a 5-point Likert scale (1 - very unlike me, 2 - moderately unlike me, 3 - somewhat unlike and like me, 4 - moderately like me and 5 - very like me). The Cronbach internal reliabilities of these scales were from .35 to .78 in a Chinese sample [37].

C. The Hamilton Anxiety Rating Scale

The scale consists of 14 items and is designed to assess the anxiety severity of an individual. Each item contains a number of symptoms, and each group of symptoms is rated from 0 (not at all) to 4 (most severe) [34]. The inter-rater reliability of the scale was 1.00 in a Chinese sample [38]. 


\section{The Hamilton Depression Rating Scale}

The scale contains 17 items, which provide an indication of depression, and serves as a guide to evaluate recovery. It is designed for adults and is used to rate the severity of their depression by probing mood, feelings of guilt, suicidal ideation, insomnia, agitation or retardation, anxiety, weight loss, and somatic symptoms. Each item is scored on a 3 or 5 point Likert scaling [35]. The Cronbach internal reliability of the scale was .71 in a previous Chinese study [39].

\subsection{Statistical Analyses}

In three groups of participant, one-way ANOVA was applied to the mean scores of anxiety and depression, and two-way ANOVA (group $\times$ factor) was applied to the mean FRQ (9 scales) and PERM style scores (11 scales). Whenever a significant main effect was found, the post-hoc analysis by the Bonferroni test was employed to evaluate between-group differences. Moreover, in each group, the multiple linear regression (stepwise method) test was used to search for the relationships between the FRQ (as predictors) and PERM styles, anxiety/ depression scores, and between PERM styles (as predictors) and anxiety/ depression scores. An absolute beta value $\geq .20$ was considered as meaningful. Taking the PERM styles as mediators between FRQ and anxiety/ depression, applying a bootstrapping sampling procedure by SPSS version 19.0 (SPSS, Inc., Chicago, IL, USA) to assess indirect effects [40], different effects were evaluated in mediation analysis, and the direct and indirect effects of 11 PERM styles on anxiety/ depression were examined. A p value less than .05 was considered as significant.

\section{Results}

The mean FRQ scale scores were significantly different among the three groups (main effect, $F[2,87]=$ 3.28, MSE = 162.40, $p<.05$; scale effect, $F[8,696]=43.04, \mathrm{MSE}=973.24, \mathrm{p}<.001$; group and scale interaction effect, $F[16,696]=9.03, \mathrm{MSE}=204.14, p<.001)$. The post-hoc test showed that in GAD, Paternal Abuse $(p<.05,95 \%$ Confidence Interval $(C l)=[.89,6.51]$ and Paternal Dominance $(p<.001,95 \%$ $\mathrm{Cl}=[2.92,9.31])$ scores were higher than those in controls, and Maternal Abuse $(\mathrm{p}<.05,95 \% \mathrm{Cl}=[.80$, 6.69]), Maternal Freedom Release $(\mathrm{p}<.001,95 \% \mathrm{Cl}=[5.62,13.92])$, and Maternal Dominance $(\mathrm{p}<.001$, $95 \% \mathrm{Cl}=[2.59,8.82])$ scores were lower than those in controls. In MD, Paternal Abuse scores $(p<.05,95 \%$ $\mathrm{Cl}=[.83,6.51])$ and Paternal Dominance scores $(\mathrm{p}<.05,95 \% \mathrm{Cl}=[.20,6.71])$ were higher than those in controls, and Maternal Freedom Release $(p<.001,95 \% \mathrm{Cl}=[2.99,11.29])$ was lower than that in controls (Table 2). 
Table 2

Scale scores (Mean \pm S.D.) of family, personality, and emotion related questionnaires in healthy volunteers (controls, $n=32$ ), and patients with Generalized Anxiety Disorder (GAD, $n$ $=30$ ) and Major Depressive Disorder (MD, $n=31)$.

\begin{tabular}{|c|c|c|c|}
\hline & Controls & GAD & MD \\
\hline \multicolumn{4}{|l|}{ Family Relationship Questionnaire } \\
\hline General Attachment & $17.50 \pm 4.36$ & $17.77 \pm 4.28$ & $16.00 \pm 4.54$ \\
\hline Paternal Encouragement & $11.28 \pm 4.64$ & $11.40 \pm 3.87$ & $13.34 \pm 4.65$ \\
\hline Paternal Abuse & $7.50 \pm 3.89$ & $11.20 \pm 4.85 a$ & $11.17 \pm 4.86 \mathrm{a}$ \\
\hline Paternal Freedom Release & $15.69 \pm 5.59$ & $12.07 \pm 5.92$ & $13.59 \pm 6.31$ \\
\hline Paternal Dominance & $10.19 \pm 4.01$ & $16.30 \pm 5.76 a$ & $13.64 \pm 5.61 a$ \\
\hline Maternal Encouragement & $14.59 \pm 4.37$ & $13.60 \pm 4.35$ & $13.50 \pm 4.19$ \\
\hline Maternal Abuse & $8.28 \pm 4.24$ & $4.53 \pm 4.19 a$ & $6.80 \pm 5.69$ \\
\hline Maternal Freedom Release & $17.94 \pm 4.64$ & $8.17 \pm 7.78 \mathrm{a}$ & $10.80 \pm 7.34 a$ \\
\hline Maternal Dominance & $10.94 \pm 3.71$ & $5.23 \pm 5.57 a$ & $7.87 \pm 5.65$ \\
\hline \multicolumn{4}{|l|}{ Parker Personality Measure } \\
\hline Paranoid & $20.05 \pm 8.65$ & $23.40 \pm 9.07$ & $29.78 \pm 11.87 a, b$ \\
\hline Schizoid & $20.98 \pm 8.14$ & $19.73 \pm 4.40$ & $29.03 \pm 14.43 a, b$ \\
\hline Schizotypal & $13.47 \pm 13.26$ & $9.53 \pm 4.46$ & $19.50 \pm 16.01 b$ \\
\hline Antisocial & $19.90 \pm 9.24$ & $17.97 \pm 6.26$ & $27.31 \pm 11.84 a, b$ \\
\hline Borderline & $19.66 \pm 8.83$ & $22.43 \pm 8.36$ & $33.43 \pm 10.13 a, b$ \\
\hline Histrionic & $14.61 \pm 11.37$ & $13.43 \pm 4.34$ & $21.74 \pm 13.72 a, b$ \\
\hline Narcissistic & $17.86 \pm 10.30$ & $17.87 \pm 7.50$ & $23.74 \pm 11.21$ \\
\hline Avoidant & $23.27 \pm 9.46$ & $26.63 \pm 8.83$ & $34.81 \pm 10.20 \mathrm{a}, \mathrm{b}$ \\
\hline Dependent & $21.72 \pm 8.76$ & $24.33 \pm 7.09$ & $32.84 \pm 9.71 \mathrm{a}, \mathrm{b}$ \\
\hline Obsessive-Compulsive & $18.68 \pm 10.92$ & $18.40 \pm 5.43$ & $27.41 \pm 14.30 \mathrm{a}, \mathrm{b}$ \\
\hline Passive-Aggressive & $20.20 \pm 7.71$ & $20.30 \pm 6.75$ & $28.35 \pm 12.24 a, b$ \\
\hline Hamilton Anxiety Rating Scale & $4.44 \pm .62$ & $25.63 \pm 3.85 a$ & $12.35 \pm 2.60 \mathrm{a}, \mathrm{b}$ \\
\hline Hamilton Depression Rating Scale & $4.47 \pm .57$ & $11.07 \pm 3.26 a$ & $25.61 \pm 5.35 a, b$ \\
\hline
\end{tabular}

Note: $a, p<.05$ vs. controls; $b, p<.05$ vs. GAD. 
Mean anxiety scores were significantly different among the three groups $(F[2,92]=494.03$, MSE $=$ $3534.69, p<.001)$, with $\mathrm{GAD}(\mathrm{p}<.001 ; 95 \% \mathrm{Cl}=[19.54,22.85])$ and $\mathrm{MD}(\mathrm{p}<.001 ; 95 \% \mathrm{Cl}=[6.27,9.56])$ scored significantly higher than controls did, and GAD scored significantly higher than MD did $(p<.001$; $95 \% \mathrm{Cl}=[11.61,14.59])$. Mean depression scores were significantly different among the three groups ( $\mathrm{F}$ $[2,92]=280.36, \mathrm{MSE}=3667.05, \mathrm{p}<.001)$, with $\operatorname{GAD}(\mathrm{p}<.001 ; 95 \% \mathrm{Cl}=[4.36,8.44])$ and $\mathrm{MD}(\mathrm{p}<.001 ; 95 \%$ $\mathrm{Cl}=[18.92,23.37])$ scored significantly higher than controls did, and MD scored significantly higher than GAD did $(p<.001 ; 95 \% \mathrm{Cl}=[12.29,16.81])$ (see Table 2$)$.

The mean PERM style scores were also significantly different among the three groups $(F[2,90]=10.12$, MSE $=8630.13, p<.001$; scale effect, $F[10,900]=64.02, M S E=1588.47, p<.001$; interaction effect, $F[20$, $900]=2.95, \mathrm{MSE}=73.08, \mathrm{p}<.001)$. The post-hoc test showed that scores of Paranoid $(\mathrm{p}<.001,95 \% \mathrm{Cl}=$ $[3.60,15.85])$, Schizoid $(p<.05,95 \% \mathrm{Cl}=[1.95,14.15])$, Antisocial $(\mathrm{p}<.05,95 \% \mathrm{Cl}=[1.62,13.20])$, Borderline $(p<.001,95 \% \mathrm{Cl}=[8.15,19.40])$, Histrionic $(p<.05,95 \% \mathrm{Cl}=[.59,13.68])$, Avoidant $(p<.001$, $95 \% \mathrm{Cl}=[5.69,17.40])$, Dependent $(p<.001,95 \% \mathrm{Cl}=[5.83,16.41])$, Obsessive-Compulsive $(p<.05,95 \% \mathrm{Cl}$ $=[2.04,15.44])$ and Passive-Aggressive $(p<.001,95 \% \mathrm{Cl}=[2.47,13.82])$ in MD were higher than those in controls. Paranoid $(p<.05,95 \% \mathrm{Cl}=[.16,12.60])$, Schizoid $(p<.001,95 \% \mathrm{Cl}=[3.09,16.49])$, Schizotypal $(p<.05,95 \% \mathrm{Cl}=[2.25,17.68])$, Antisocial $(p<.001,95 \% \mathrm{Cl}=[3.46,15.24])$, Borderline $(p<.001,95 \% \mathrm{Cl}=$ $[5.29,16.71])$, Histrionic $(p<.05,95 \% \mathrm{Cl}=[1.66,14.96])$, Avoidant $(p<.001,95 \% \mathrm{Cl}=[2.23,14.13])$, Dependent $(p<.001,95 \% \mathrm{Cl}=[3.13,13.88])$, Obsessive-Compulsive $(p<.05,95 \% \mathrm{Cl}=[2.20,15.82])$, and Passive-Aggressive $(p<.001,95 \% \mathrm{Cl}=[2.29,13.82])$ in MD were higher than those in GAD (also see Table 2).

The detailed associations between FRQ and PERM/ anxiety/ depression scores in controls, GAD and MD were shown in Table 3. Meanwhile, the Borderline style predicted anxiety in controls (adjusted $\mathrm{R}^{2}, .19$; beta, .47; B, .03; Standard error, .01), and the Dependent style predicted depression in MD (adjusted $\mathrm{R}^{2}$, .14; beta, .42; B, .23; Standard error, .09). No significant mediation effect was found among all the personality disorder functioning styles, family relationships and emotional states in controls, GAD or MD. 
Table 3

The stepwise multiple linear regression analyses for the relationships between the family, personality and emotion related questionnaires in healthy volunteers (controls, $n=32$ ), and patients with Generalized Anxiety Disorder (GAD, $n=30)$ and Major Depressive Disorder (MD, $n=31)$.

\begin{tabular}{|c|c|c|c|c|c|c|}
\hline & & Controls & & GAD & & MD \\
\hline & $\begin{array}{l}\mathrm{a}^{-} \\
\mathrm{R}^{2}\end{array}$ & $\begin{array}{l}\text { beta }(B, S E) \text {, } \\
\text { predictor }\end{array}$ & $\begin{array}{l}\mathrm{a}^{-} \\
\mathrm{R}^{2}\end{array}$ & $\begin{array}{l}\text { beta (B, SE), } \\
\text { predictor }\end{array}$ & $\begin{array}{l}\mathrm{a}- \\
\mathrm{R}^{2}\end{array}$ & $\begin{array}{l}\text { beta (B, SE), } \\
\text { predictor }\end{array}$ \\
\hline \multicolumn{7}{|l|}{$\begin{array}{l}\text { Personality } \\
\text { Measure }\end{array}$} \\
\hline Paranoid & .24 & $\begin{array}{l}-.51(-.80, .24), \\
\text { Paternal } \\
\text { Freedom } \\
\text { Release }\end{array}$ & .33 & $\begin{array}{l}60(1.24, .32) \\
\text { Maternal } \\
\text { Encouragement }\end{array}$ & .21 & $\begin{array}{l}.49(1.28, .45) \\
\text { Maternal } \\
\text { Encouragement }\end{array}$ \\
\hline Schizotypal & & & .20 & $\begin{array}{l}.48(.49, .17) \\
\text { Maternal } \\
\text { Encouragement }\end{array}$ & & \\
\hline Borderline & & & .24 & $\begin{array}{l}.52(.56, .17) \\
\text { Maternal Freedom } \\
\text { Release }\end{array}$ & & \\
\hline Narcissistic & .18 & $\begin{array}{l}-.46(-84, .30), \\
\text { Paternal } \\
\text { Freedom } \\
\text { Release }\end{array}$ & & & & \\
\hline Avoidant & .20 & $\begin{array}{l}-.47(-80, .27), \\
\text { Paternal } \\
\text { Freedom } \\
\text { Release }\end{array}$ & .26 & $\begin{array}{l}.53(.61,18) \\
\text { Maternal Freedom } \\
\text { release }\end{array}$ & .26 & $\begin{array}{l}-.49(-.82, .28), \\
\text { Paternal Dominance }\end{array}$ \\
\hline \multirow[t]{2}{*}{$\begin{array}{l}\text { Hamilton } \\
\text { Anxiety Rating } \\
\text { Scale }\end{array}$} & \multirow[t]{2}{*}{.39} & $\begin{array}{l}.80(.13, .03) \\
\text { Paternal Abuse }\end{array}$ & & & \multirow[t]{2}{*}{.32} & $\begin{array}{l}-.87(-.33, .09) \\
\text { Paternal Freedom } \\
\text { Release }\end{array}$ \\
\hline & & $\begin{array}{l}-.46(-.07, .03) \\
\text { Maternal Abuse }\end{array}$ & & & & $\begin{array}{l}.56(.18, .08), \\
\text { Maternal Freedom } \\
\text { Release }\end{array}$ \\
\hline
\end{tabular}

Note: all predictors are significant ones at $\mathrm{p}<.01 ; \mathrm{a}-\mathrm{R}^{2}$, adjusted $\mathrm{R}^{2} ; \mathrm{B}$, beta; $\mathrm{SE}$, Standardized error.

\section{Discussion}

Compared to controls, besides the higher anxiety in GAD and higher depression in MD, we found that both patient groups scored higher on FRQ Paternal Abuse and Paternal Dominance, and lower on Maternal Freedom Release, and we found that GAD scored lower on Maternal Abuse and Maternal Dominance, which supported our first hypothesis. All PERM scale scores except Narcissistic were higher in MD than those in GAD, and all scale scores except Schizotypal and Narcissistic were higher in MD than in controls, which were consistent with our second hypothesis. Maternal Encouragement was associated with the 
Paranoid and Schizotypal styles, and Maternal Freedom Release the Avoidant and Borderline in GAD; and Maternal Encouragement the Paranoid, Paternal Dominance the Avoidant, Paternal Freedom Release (-) and Maternal Freedom Release the anxiety, and the Dependent the depression in MD, which were in line with our third hypothesis.

In controls, Paternal Freedom Release was associated with the Paranoid, Narcissistic, and Avoidant styles. Indeed, previous results have shown that patients with personality disorders perceived more paternal freedom control and more paternal autonomy denial than healthy participants did [17], which might indicate that the balance between paternal freedom release and dominance is essential to mental health. Besides, the Borderline style predicted anxiety score in controls, which was consistent with that borderline personality disorder patients reported higher levels of anxiety sensitivity [41]. However in controls, Paternal Abuse and Maternal Abuse (-) predicted anxiety were inconsistent with the report that maternal inappropriate discipline was the most important predictor of anxiety [42], nonetheless, they were in line with that parental physical aggression was significantly associated with an individual's anxiety, although the effects of maternal and paternal abuses were different [43].

In GAD, higher Paternal Abuse and Paternal Dominance, and lower Maternal Freedom Release and Maternal Dominance were found when compared to controls, which were in line with the previous reports that parental over-control [44, 45], rejection [46], and inconsistent parental support and warmth [47] were associated with anxiety in children and adolescents. The outcomes were also supported by findings that the parental emotional warmth and acceptance of children's negative emotions rather than criticizing or minimizing their feelings, promoted the emotional regulation ability and reduced the vulnerability to anxiety of the children [48]. Moreover, Maternal Encouragement was associated with the Paranoid and Schizotypal styles in GAD, which were partly supported by the reports that maternal overprotection increased social anxiety of children [6]. We have also found that Maternal Freedom Release was associated with the Avoidant and Borderline styles, which might be partly explained by the association between the lack of maternal care and the behavioral and emotional problems in late adulthood [5].

Similar to GAD, higher Paternal Abuse and Paternal Dominance, and lower Maternal Freedom Release were found in MD than those in controls, which were supported by the results that adolescents with perceived warm parenting style were less likely to suffer from depression after stressful life events [8]. Further, MD scored significantly higher on most PERM scales than both GAD and controls did, which was in accordance with the relationship between extreme personality traits and affective morbidities such as depression [49], and with that personality disorder patients had higher depression [50]. Moreover, Dependent style was associated with depression in MD, which was in line with the reports that patients with dependent personality disorder were depressed [51]. In addition, Maternal Encouragement was associated with Paranoid style, and Paternal Dominance was associated with Avoidant style, which were supported by that maternal overprotection contributed to social deficits such detachment and avoidance in children [6]. This outcome also suggested that the paternal over-control was unfavorable to the development of personality in MD, as indicated in an earlier investigation [52]. Furthermore, the association between anxiety and Paternal Freedom Release (-) and Maternal Freedom Release in MD was 
in line with the suggestion of decreasing control from father and increasing care from mother in anxiety disorder patients [6].

Nevertheless, there are several design flaws in the present study. Firstly, the sample size of each group was small, and our results need further confirmation from other independent laboratories. Secondly, all measures used in our study were depending on self-reports, which might suffer from the recall bias. Thirdly, although medications prescribed to our patients have little effect on cognition, we still could not rule out the possible effects on their concurrent emotional states.

We have found that personality traits and emotional states were associated with family relationships differently in major depressive and generalized anxiety disorders, which imply different forms of family therapy for the two clinical conditions.

\section{Declarations}

\section{Acknowledgments}

Dr Z Yu was sponsored by a grant from the Specific Foundation for Key Project of Hangzhou concerning Specific Medical Disease (20160533B30), and Dr W Wang was sponsored by a grant from the Natural Science Foundation of China (No. 81771475).

\section{Ethics approval and informed consent}

The study was conducted in compliance with Declaration of Helsinki, and was reviewed and approved by Ethics Committee of Zhejiang University School of Public Health (ZGL201606-1-4), and all participants gave their written informed consent to participate in this study.

\section{Competing Interests}

The authors declare no competing of interest.

\section{Authors' contributions}

WW conceived the study, ZY, YX, QZ, HM, BZ and XS contributed to the study design and collected the data, ZY and BZ analyzed the data, and ZY and WW drafted the paper.

\section{References}


[1] Darling N, Steinberg L. Parenting style as context: an integrative model. Psychological Bulletin 1993, 113: $487-496$.

[2] Parker G, Barrett E, Hickie I. From nurture to network: Examining links between perceptions of parenting received in childhood and social bonds in adulthood. American Journal of Psychiatry 1992, 149: 877-885.

[3] Enns MW, Cox BJ, Clara I. Parental bonding and Adult psychopathology: Results from the US National Comorbidity Survey. Psychological Medicine 2002, 32: 997-1008.

[4] Narita T, Sato T, Hirano S, Gota M, Sakado K, Uehara T. Parental child-rearing behavior as measured by the Parental Bonding Instrument in a Japanese population: Factor structure and relationship to a lifetime history of depression. Journal of Affective Disorders 2000, 57: 229-234.

[5] Silberg JL, Eaves LJ. Analysing the contributions of genes and parent-child interaction to childhood behavioural and emotional problems: A model for the children of twins. Psychological Medicine 2004, 34: 347-356.

[6] Rork KE, Morris TL. Influence of parenting factors on childhood social anxiety: Direct observation of parental warmth and control. Child and Family Behavior Therapy 2009, 31: 220-235.

[7] Wolfradt U, Hempel S, Miles JNV. Perceived parenting styles, depersonalization, anxiety and coping behaviour in adolescents. Personality and Individual Differences 2003, 34: 521-532.

[8] Wagner BM, Cohen P, Brook JS. Parent/adolescent relationships: Moderators of the effect of stressful life events. Journal of Adolescent Research 1996, 11: 347-374.

[9] Muris P, Merckelbach H. Perceived parental rearing behaviour and anxiety disorders symptoms in normal children. Personality and Individual Differences 1998, 25: 1199-1206.

[10] Hulsenbeck P, Meesters C, Merkelbach H, Munis P. Worry in Children is related to Perceived Parental Rearing and Attachment. Behaviour Research and Therapy 2000, 38: 487-497.

[11] Bijl RV, Cuijpers P, Smit F. Psychiatric disorders in adult children of parents with a history of psychopathology. Social Psychiatric Epidemiology 2002, 37:7-12.

[12] Maccoby EE. The role of parents in the socialization of children: a historical review. Developmental Psychology 1992, 28: 1006-1017.

[13] Dwairy M, Menshar KE. Parenting style, individuation, and mental health of Egyptian adolescents. Journal of Adolescence 2006, 29:103-117.

[14] Gao Y, Raine A, Chan F, Venables PH, Mednick SA. Early maternal and paternal bonding, childhood physical abuse and adult psychopathic personality. Psychological Medicine 2010, 40: 1007-1016. 
[15] Lang S, Af Klinteberg B, Alm PO. Adult psychopathy and violent behavior in males with early neglect and abuse. Acta Psychiatrica Scandinavica 2002, 106: 93-100.

[16] O'Neill ML, Lidz V, Heilbrun K. Predictors and correlates of psychopathic characteristics in substance abusing adolescents. International Journal of Forensic Mental Health 2003, 2: 35-45.

[17] Yu R, Wang Z, Qian F, Jang KL, Livesley WJ, Paris J, Shen M, Wang W. Perceived parenting styles and disordered personality traits in adolescent and adult students and in personality disorder patients. Social Behavior and Personality 2007, 35: 587-598.

[18] Zheng L, Chai H, Chen W, Yu R, He W, Jiang Z, Yu S, Li H, Wang W. Recognition of facial emotion and perceived parental bonding styles in healthy volunteers and personality disorder patients. Psychiatry and Clinical Neurosciences 2011, 65: 648-654.

[19] Anthony JL, Lonigan CJ, Hooe ES, Phillips BM. An affect-based, hierarchical model of temperament and its relations with internalizing symptomatology. Journal of Clinical Child and Adolescent Psychology 2002, 31:480-490.

[20] Griffith JW, Zinbarg RE, Craske MG, Mineka S, Rose RD, Waters AM, Sutton JM. Neuroticism as a common dimension in the internalizing disorders. Psychological Medicine 2010. 40: 1125-1136.

[21] Gershuny BS, Sher KJ. The relation between personality and anxiety: Finding from a 3-year prospective study. Journal of Abnormal Psychology 1992, 107: 252-262.

[22] Gomez R, Francis LM. Generalized anxiety disorder: Relationships with Eysenck's, Gray's and Newman's theories. Personality and Individual Differences 2003, 34: 3-17.

[23] Duggan F, Lee AS, Murray RM. Does personality predict long-term outcome in depression? British Journal of Psychiatry 1990, 157: 19-24.

[24] Scott J, Eccleston D, Boys R. Can we predict the persistence of depression? British Journal of Psychiatry 1992, 161: 633-637.

[25] Regier DA, Rae DS, Narrow WE, Kaelber CT, Schatzberg AF. Prevalence of anxiety disorders and their comorbidity with mood and addictive disorders. British Journal of Psychiatry Supplement 1998, 173: 24.

[26] Minelli A, Pedrini L, Magni LR, Rotondo A. Personality traits in an Italian sample: Relationship with anxiety and depression. Clinical Practice and Epidemiology in Mental Health 2009, 5: 26-30.

[27] Chen CY, Lin SH, Li P, Huang WL, Lin YH. The role of the harm avoidance personality in depression and anxiety during the medical internship. Medicine 2015, 94: e389.

[28] He W, Chai H, Zhang Y, Yu S, Chen W, Wang W. Line bisection performance in patients with generalized anxiety disorder and treatment-resistant depression. International Journal of Medical 
Sciences 2010, 7: 224-231.

[29] Kotov R, Gamez W, Schmidt F, Watson D. Linking "big" personality traits to anxiety, depressive, and substance use disorders: A meta-analysis. Psychological Bulletin 2010, 136: 768-821.

[30] Spinhoven P, Elzinga BM, van Hemert AM, de Rooij M, Penninx BW. A longitudinal study of facets of extraversion in depression and social anxiety. Personality and Individual Differences 2014, 71: 39-44.

[31] Karsten J, Penninx BWJH, Riese H, Ormel J, Nolen WA, Hartman CA. The state effect of depressive and anxiety disorders on big five personality traits. Journal of Psychiatric Research 2012, 46: 644-650.

[32] Chen L, Xu K, Fu L, Xu S, Gao Q, Wang W. Development of a structure-validated Family Relationship Questionnaire (FRQ) with Chinese University students. Bulletin of the Menninger Clinic 2015. 79: 232-254.

[33] Parker G, Hadzi-Pavlovic D. A question of style: Refining the dimensions of personality disorders style. Journal of Personality Disorders 2001, 15: 300-318.

[34] Hamilton M. The assessment of anxiety states by rating. British Journal of Medical Psychology 1959, 32: 50-55.

[35] Hamilton M. A rating scale for depression. Journal of Neurology, Neurosurgery, and Psychiatry 1960, 23: $56-62$.

[36] American Psychiatric Association. Diagnostic and Statistical Manual of Mental Disorders, fifth ed. American Psychiatric Association, Arlington, VA. 2013.

[37] Wang W, Hu L, Mu L, Chen DH, Song Q, Zhou MP, Zhang WJ, Hou J, Li ZG, Wang J, Liu JH, He CS. Functioning styles of personality disorders and five-factor normal personality traits: A correlation study in Chinese students. BMC Psychiatry 2003, 3: 11.

[38] Wang J, Jiang C, Chen L, Wu S, Lin J, Gao L, Xie B, Zheng D, Yang R, Li S, Pan X, Liao Y. A crosssectional study to investigate the correlation between depression comorbid with anxiety and serum lipid levels. Comprehensive Psychiatry 2016, 69: 163-168.

[39] Zheng YP, Zhao JP, Phillips M, Liu JB, Cai MF, Sun SQ, Huang MF. Validity and reliability of the Chinese Hamilton Depression Rating Scale. British Journal of Psychiatry 1988, 152: 660.

[40] Preacher KJ, Hayes AF. Asymptotic and resampling strategies for assessing and comparing indirect effects in multiple mediator models. Behavior Research Methods 2008, 40: 879-891.

[41] Gratz KL, Tull MT, Gunderson JG. Preliminary data on the relationship between anxiety sensitivity and borderline personality disorder: The role of experiential avoidance. Journal of Psychiatric Research 2008, 42: $550-559$. 
[42] Nilsson D, Nordås E, Pribe G, Svedin CG. Child physical abuse - High school students' mental health and parental relations depending on who perpetrated the abuse. Child Abuse and Neglect 2017, 70: 28-38.

[43] Al-Fayez GA, Ohaeri JU, Gado OM. Prevalence of physical, psychological, and sexual abuse among a nationwide sample of Arab high school students: association with family characteristics, anxiety, depression, self-esteem, and quality of life. Social Psychiatry and Psychiatric Epidemiology 2012, 47: 5366 .

[44] Varela RE, Niditch LA, Hensley-Maloney L, Moore KW, Creveling CC. Parenting practices, interpretive biases, and anxiety in Latino children. Journal of Anxiety Disorders 2013, 27: 171-177.

[45] Laurin JC, Joussemet M, Tremblay RE, Boivin M. Early forms of controlling parenting and the development of childhood anxiety. Journal of Child and Family Studies 2015, 24: 3279-3292.

[46] Hale WW 3rd, Engels R, Meeus W. Adolescent's perceptions of parenting behaviours and its relationship to adolescent Generalized Anxiety Disorder symptoms. Journal of Adolescence 2006, 29: 407-417.

[47] Knappe S, Beesdo-Baum K, Fehm L, Lieb R, Wittchen HU. Characterizing the association between parenting and adolescent social phobia. Journal of Anxiety Disorders 2012, 26: 608-616.

[48] Wood JJ, McLeod BD, Sigman M, Hwang WC, Chu BC. Parenting and childhood anxiety: Theory, empirical findings, and future directions. Journal of Child Psychology and Psychiatry 2003, 44: 134-151.

[49] Kim B, Joo YH, Kim SY, Lim JH, Kim EO. Personality traits and affective morbidity in patients with bipolar I disorder: the five-factor model perspective. Psychiatry Research 2011, 185: 135-140.

[50] Fan H, Zhu Q, Ma G, Shen C, Zhang B, Wang, W. Predicting personality disorder functioning styles by the Chinese Adjective Descriptors of Personality: a preliminary trial in healthy people and personality disorder patients. BMC Psychiatry 2016, 16: 302.

[51] Blatt SJ, Quinlan DM, Chevron ES, McDonald C, Zuroff D. Dependency and self-criticism: psychological dimensions of depression. Journal of Consulting Clinical Psychology 1982, 50: 113-124.

[52] Sorkhabi N. Parent socialization effects in different cultures: significance of directive parenting. Psychological Reports 2012, 110: 854-878. 